\title{
Al-Madãris
}

VOL. 2, NO. 2, 2021

E-ISSN: 2745-9950

https:/journal.staijamitar.ac.id/index.php/almadaris

\section{PENGEMBANGAN LITERASI KATABA UNTUK MENUNJANG PENDIDIKAN BERKUALITAS PERSPEKTIF QS. AL-'ALAQ AYAT 1-5}

\author{
Ali Hamidi \\ Institut Agama Islam Negeri (IAIN) Salatiga \\ abdulhamidbinmastur@gmail.com \\ Muhammad Syariful Anam \\ Institut Agama Islam Negeri (IAIN) Salatiga \\ syarifulanam2700@gmail.com \\ Firdan Fadlan Sidik \\ Institut Agama Islam Negeri (IAIN) Salatiga \\ firdan.fadlan@gmail.com
}

\begin{abstract}
The Qur'an has a comprehensive view of the conception of education. Among the core of education is literacy. Student's literacy skills are able to lead the nation's generation to be literate and discover their potential. PISA research results in 2018 prove that Indonesia is ranked more than 10 and below in several assessment areas, such as reading, mathematics and science. The PISA 2018 data shows that the level of literacy in Indonesia is still low. Apart from the responsibility of the Ministry of Education and Culture (Kemdikbud) to develop educational policies, students also have a role as booster of the quality of education. Seeing the conception of literacy education from the perspective of the Qur'an, the KATABA Ma'had Al-Jami'ah became the object of research. The existence of this community acts as a support for the literacy atmosphere in the Ma'had environment which contributes to developing the world of writing and research. Through the qualitative method used in this study, the authors found that KATABA is a manifestation of the practice of the concept of literacy in Al-'Alaq verses 1-5. The existence of literacy community among students contributes to the academic development of students. An
\end{abstract}


increasing achievement index is one indicator of the success of the community in increasing the level of education in higher education.

\section{Keywords: Al-'Alaq, Education, KATABA, Literacy}

\section{A. Pendahuluan}

Era revolusi industri 5.0 telah mewarnai atmosfer seluruh bidang kehidupan di abad ke-21. Melalui society 5.0, kecerdasan buatan (artificial intelligent) akan sangat memengaruhi sendi kehidupan melalui transformasi big data serta the Internet of Things (IoT) akan menjadi suatu kearifan baru yang akan digunakan oleh manusia dalam mengakselerasi kemampuan untuk membuka berbagai peluang (Karinov, 2019). Diantara pengaruh society 5.0 adalah bidang pendidikan. Digitalisasi berbagai fasilitas menjadi dampak berkembangnya Internet of Things dan menyebabkan kemunculan berbagai kreativitas disruptif.

Permasalahan dan tugas besar pendidikan di Indonesia tidak hanya menghadapi tantangan revolusi industri 5.0, melainkan juga hasil survei Programme for International Student Assessment (PISA) 2018. Dari berbagai kategori penilaian seperti membaca, matematika dan sains, Indonesia menempati peringkat 6 negara terbawah di dunia setelah Filipina, Dominika, Kosovo, Lebanon dan Maroko dengan poin membaca 371, matematika 379 dan sains 396 (OECD, 2019). Meski hasil data ini mengalami sedikit peningkatan dari hasil penelitian PISA sebelumnya, namun hasilnya masih tidak sesuai dengan yang diharapkan, sehingga perlu adanya pengembangan dan inovasi pendidikan di Indonesia untuk mengejar ketertinggalan kualitas pendidikan dunia.

Dari sisi subjek, generasi milenial dan generasi $Z$ sebagai usia pelajar dan mahasiswa di Indonesia juga memiliki problematika tersendiri yang menghambat berjalannya proses pendidikan. Keberadaan gawai dan internet memiliki dua sisi sekaligus, yaitu manfaat dan bahaya yang perlu dikelola dengan baik sehingga perangkat milenial tidak merusak pendidikan.

Berdasarkan kajian tersebut, maka perlu adanya upaya yang harus dilakukan dalam mereduksi problematika pendidikan yang ada di Indonesia. Terlebih lagi dalam upaya meningkatkan kualitas literasi, karena bagaimanapun juga core (inti) dari pendidikan ialah kemampuan berliterasi siswa terutama membaca dan aktivitas menulis. Bahkan jika ingin menilik sejarah mengenai aktivitas literasi, 14 abad yang lalu Allah SWT memberikan wahyu pertama kepada Nabi Muhammad SAW mengenai perintah membaca.

Di sisi lain, keberadaan komunitas literasi menjadi urgensi bagi terciptanya masyarakat yang suka akan membaca (society book reader). Keberadan komunitas literasi sangat penting dalam rangka memotivasi masyarakat khususnya kaum terpelajar untuk meningkatkan kecintaan terhadap membaca dan menulis. Jika semakin banyak dan masif gerakan-gerakan literasi yang dilakukan, tentu peningkatan kualitas pendidikan akan tercapai.

Berdasarkan uraian yang telah disampaikan, dalam tulisan ini akan dibahas mengenai inisiatif dari mahasiswa sebagai sivitas akademik yang mengemban amanah Tridharma Perguruan Tinggi untuk mengadakan evaluasi dan menyegarkan kebijakan pendidikan. Mahasiswa memiliki peranan yang 
sangat penting dalam mengadakan kajian ilmiah serta aksi langsung dalam memberdayakan literasi. Dalam penelitian ini, penulis mengangkat komunitas KATABA di Ma'had Al-Jami'ah IAIN Salatiga sebagai objek penelitian. Dimana, komunitas KATABA memiliki visi yang sangat relevan dengan nilai-nilai literasi yang terkandung di dalam Al-Qur'an surat Al-'Alaq ayat 1-5.

\section{B. Review Literatur}

Literasi merupakan kaidah yang mengembangkan kemampuan dan keterampilan manusia dalam memahami pengetahuan yang diperoleh melalui membaca dan menulis (Majid, 2019). Dalam konteks sekarang, literasi memiliki cakupan yang lebih luas, literasi bisa berarti melek teknologi, politik, serta berpikir kritis dalam mengamati lingkungan sekitar. Karenanya, seseorang dapat dikatakan literat apabila mampu memahami sesuatu karena membaca dan melakukan sesuatu berdasarkan pemahaman bacaannya (Wahidin et al., 2017). Sementara itu, dalam Deklarasi Praha, bahwa literasi mencakup seseorang dalam berkomunikasi, berhubungan sosial, serta mengatasi berbagai persoalan (UNESCO, 2003).

Literasi sangat erat kaitannya dengan pendidikan. Keduanya merupakan bagian yang tidak dapat dipisahkan. Oleh karena itu, budaya literasi harus terus dilakukan secara masif guna mencapai pendidikan yang lebih berkualitas. Bahkan, Islam mengajarkan untuk senantiasa menjunjung tinggi aktivitas literasi. Melalui Al-Qur'an, Allah SWT mendorong manusia untuk selalu menuntut dan mengembangkan ilmu pengetahuan. Diantara wahyu Al-Qur'an atau ayat yang pertama kali turun kepada Nabi Muhammad SAW dengan kalimat "Bacalah" (berulang dua kali), dimana membaca dalam pengertian yang lebih luas merupakan kunci untuk membuka wawasan dan ilmu pengetahuan (Majid, 2019).

\section{Metodelogi}

Penelitian ini dilakukan melalui studi literatur mendalam, yaitu dengan menggunakan analisis deskriptif dan data yang digunakan merupakan data dari hasil pendekatan kualitatif. Pendekatan kualitatif dimaksudkan untuk mengidentifikasi secara komprehensif mengenai suatu gejala, fakta atau realita (Raco, 2010). Pengumpulan data dilakukan dengan menggunakan metode studi dokumen atau arsip. Metode pengumpulan data tersebut diperoleh dari berbagai buku, dokumen serta literatur yang relevan untuk menyusun konsep dan mengungkap objek yang diteliti (Agustinova, 2015). Selain itu, penelitian ini memuat intuitif subjektif dari penulis, yang merupakan pelibatan pendapat atau argumentasi penulis terhadap masalah yang sedang dikaji.

\section{Hasil Penelitian dan Pembahasan}

\section{Data Literasi di Indonesia}

Pusat Penilaian Pendidikan Balai Penelitian dan Pengemabngan (Balitbang) Kementerian Pendidikan dan Kebudayaan menjabarkan hasil penelitian Programme International of Student Assessment (PISA) ke dalam angka berbentuk pecahan sederhana. Sebanyak 7 dari 10 siswa usia 15 tahun, memiliki 
kemampuan literasi membaca yang masih di bawah kompetensi minimal. Mereka hanya mampu mengidentifikasi informasi rutin dari bacaan pendek serta prosedur sederhana (Badan Penilaian Pendidikan Balitbang, 2019). Namun demikian, setelah diadakan penelitian di DKI Jakarta dan DI Yogyakarta oleh Pusat Penilaian Pendidikan Balitbang Kementerian Pendidikan dan Kebudayaan, rata-rata skor kedua provinsi tersebut 35 poin lebih tinggi dari rata-rata nasional dan sejajar dengan negara ASEAN lainnya. Dengan demikian, dapat dikatakan bahwa masih terdapat kesenjangan pendidikan antara perkotaan dan daerah pedesaan.

Berbicara mengenai problematika lemahnya budaya membaca dapat dilihat dari berbagai sisi. Jika diamati dari sisi dampak pengaruh era generasi milenial, maka faktor minimnya budaya membaca adalah belum memiliki keahlian dalam menyelipkan pendidikan literasi di dalam perangkat gawai dengan pembelajaran yang sistematis dan efektif. Generasi milenial dan generasi $Z$ yang sudah terlahir dalam keadaan digital natives masih belum bisa mengimbangi antara belajar dengan bermain game serta mengaplikasikan gawai dengan kewajiban untuk belajar. Praktisi akademis (guru) menemukan kesulitan dalam mengintegrasikan teknologi digital dengan perencanaan pendidikan literasi karena beberapa faktor yang menghambat seperti fokus kurikulum literasi sekolah yang masih berbasis kertas dan buku, keterbatasan waktu untuk menjelajahi sumber informasi digital, ketiadaan pembinaan tentang potensi teknologi untuk memperkenalkan literasi dan juga kelemahan untuk menggunakan alat-alat digital dengan efektif (Flewitt et al., 2014).

Generasi milenial memiliki peran penting dalam menentukan kualitas pendidikan. Berdasarkan data Badan Perencanaan Pembangunan Nasional (Bappenas), terdapat 63 juta milenial (penduduk usia 20-35 tahun) di Indonesia. Dari hasil riset tercatat ada 94,4 persen milenial Indonesia telah terkoneksi dengan internet (IDN Research Institute, 2019). Berdasarkan klasifikasi penggunaan internet, terdapat 4 kategori, yaitu light user ( $<1$ jam sehari), medium user (1-3 jam sehari), heavy user (4-6 jam sehari), dan addicted user ( $>7$ jam sehari). Mayoritas generasi milenial di Indonesia menurut IDN Research termasuk dalam kategori heavy user dan addicted user. Semakin muda usia milenial, tingkat kecanduan internet semakin tinggi. Junior milenial menghabiskan waktu lebih dari 11 jam untuk menggunakan internet atau sebesar 9,6 persen, sedangkan senior milenial hanya 5,2 persen.

Angka literasi menentukan tingkat pendidikan di Indonesia yang merupakan salah satu permasalahan nasional yang menjadi titik fokus pemerintah. Bahkan dunia menjadikan pendidikan sebagai salah satu poin dalam Sustainable Devepolment Goals (SDGs). Pendidikan menjadi hal penting karena memiliki pengaruh kuat terhadap pembangunan bangsa, mulai dari sektor ekonomi, budaya, politik, agama, dan lainnya. Pemerintah melalui Kementerian Pendidikan dan Kebudayaan terus mengevaluasi sistem pendidikan untuk mengoptimalkan kualitas pendidikan sesuai dengan zaman dan kondisi yang dihadapi.

Digitalisasi berbagai fasilitas menjadi dampak dari berkembangnya Internet of Things dan menyebabkan kemunculan berbagai kreativitas disruptif. Agar Al-Madãris, Volume 2 (2), 2021 
lulusan satuan pendidikan bisa kompetitif, maka kurikulum perlu mengadakan orientasi baru, sebab adanya era revolusi indutri 5.0 tidak hanya cukup literasi lama (membaca, menulis, dan matematika) sebagai modal dasar untuk berkiprah di masyarakat (Ahmad, 2018). Terdapat tiga poin literasi baru yang dikemukakan oleh Direktur Jenderal Pembelajaran dan Kemahasiswaan, Kementerian Riset, Teknologi, dan Pendidikan Tinggi tahun 2018, yaitu literasi data (membaca, menulis dan menggunakan informasi big data di dunia digital), literasi teknologi (memahami cara kerja mesin, aplikasi teknologi: coding, artificial intelligence, \& engineering principles) dan literasi manusia (humanities, komunikasi, dan desain).

\section{Analisis Efektivitas KATABA dalam Menunjang Literasi}

KATABA adalah komunitas pegiat literasi di Kota Salatiga, Jawa Tengah yang lahir pada 16 Maret 2017 atas inisiatif mahasantri Ma'had Al-Jami'ah yang mengenyam pendidikan di program Kelas Khusus Internasional (KKI) Institut Agama Islam Negri (IAIN) Salatiga. Pengalaman dan prestasinya di dunia literasi mulai dari prestasi lokal hingga internasional menjadikannya lulus sebagai mahasiswa berprestasi. Gagasan komunitas KATABA lahir setelah mengikuti event Pelatihan Jurnalistik Santri Nusantara di Jakarta pada tahun 2017.

KATABA lahir di Ma'had Al-Jami'ah IAIN Salatiga, yaitu satu-satunya asrama mahasiswa yang berada di bawah naungan kampus IAIN Salatiga. Ma'had Al-Jami'ah terbagi menjadi dua lokal, yaitu ma'had putra dan ma'had putri. Komunitasnya pun tercabang menjadi dua, yaitu KATABA untuk ma'had putra yang berjumlah 50 anggota, dan KATABA untuk ma'had putri yang berjumlah 66 anggota. Namun esensi, materi, dan kepengurusannya tetap terpusat.

Dari segi bahasa, KATABA berasal dari bahasa Arab yang artinya menulis. Adapun makna filosofisnya adalah wahana diskusi, sharing, dan pelatihan menulis yang dikemas dalam kegiatan pembelajaran dengan metode non-formal learning dan konsep every member is teacher. Kegiatan di komunitas KATABA menunjang Tri Dharma Perguruan Tinggi. Di bidang pendidikan, KATABA memberikan pembinaan dan edukasi literasi kepada mahasiswa secara umum dan juga sekelompok masyarakat secara sukarela. Selain itu, KATABA juga turut serta mengembangkan dunia inovasi lewat penelitian-penelitian yang dilakukan oleh anggota. Buku antologi karya berjudul "Mengairi Bumi Literasi" adalah salah satu produk output dari prestasi KATABA.

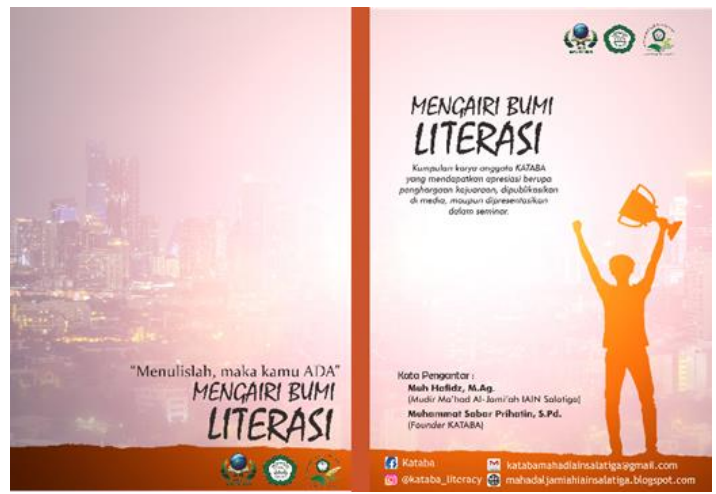

Gambar l. Buku Antologi "Mengairi Bumi Literasi” 
Di bidang pengabdian kepada masyarakat, KATABA mengabdikan dirinya sebagai lembaga non-profit yang membantu mengembangkan potensi dan nama baik kampus serta memberikan pelatihan untuk masyarakat sekitar. Hal ini seirama dengan motto KATABA, yaitu Let's Write, Let's Create (mari menulis, mari menciptakan).

\section{Langkah KATABA dalam Gerakan Literasi}

KATABA memiliki kegiatan dalam jangka rutinan, yaitu harian, mingguan, bulanan, dan tahunan. Program rutiannya adalah One Day Fifteen Minutes Reading, setiap hari membaca buku selama 15 menit. Dalam pengaplikasiannya dilakukan secara individual. Anggota KATABA dituntut untuk menceritakan ulang isi buku dan jika hasil tulisannya menarik bagi pembaca, maka dimungkinkan untuk dijadikan produk tulisan. Program ini bersifat "anjuran" dan suplemen kegiatan KATABA. Tidak ada aturan terkhusus dalam program ini. Program ini menjadi penjabaran yang gamblang dari implementasi surat Al-'Alaq ayat 1-5 yang mengintegrasikan antara membaca dan menulis.

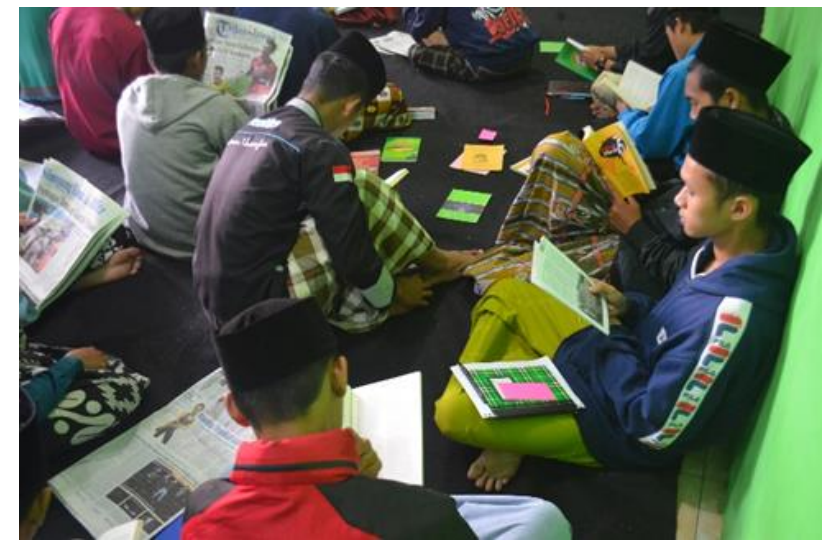

Gambar 2. Kegiatan One Day Fifteen Minutes Reading

Kegiatan mingguan KATABA adalah Sabtu Literasi, yaitu kegiatan diskusi literasi. Kegiatan ini dilaksanakan di ruangan terbuka (outdoor) yang dimulai dengan kegiatan game. Tujuan dari pemilihan tempat dan game ini adalah untuk menghadirkan suasana senang dan memfasilitasi anggota untuk memandang alam. Menurut para penulis ahli seperti Tere Liye dan Habiburrahman El-Shirazy, salah satu cara untuk mendapatkan inspirasi adalah dengan melihat alam dan jalan-jalan. Demikian halnya kegiatan KATABA yang ditujukan untuk mencari inspirasi. 


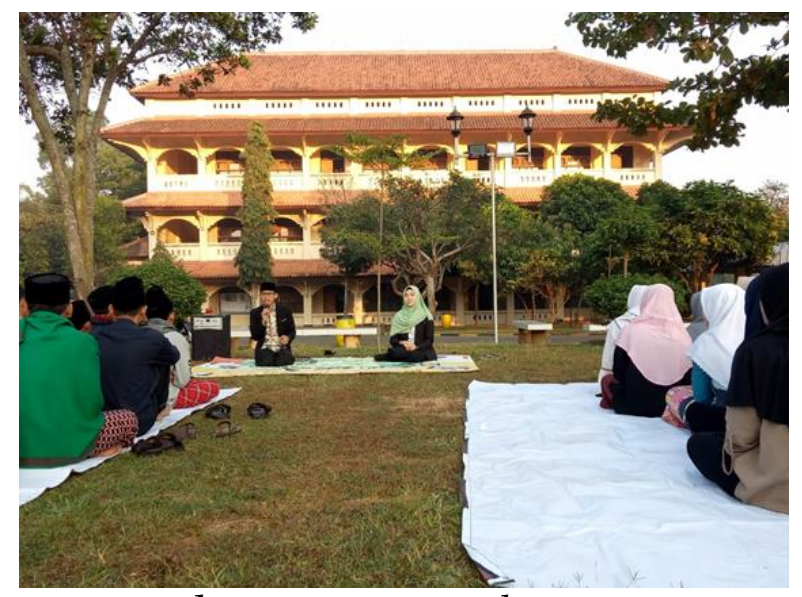

Gambar 3. Kegiatan Sabtu Literasi

Kegiatan bulanan KATABA adalah One Month One Creation, satu bulan satu karya. Setiap anggota dituntut untuk membuat karya minimal dalam jangka satu bulan untuk satu karya. Adapun karya yang dihasilkan adalah fiksi maupun nonfiksi. Seluruh anggota diberikan kebebasan untuk memilih. Melalui program "KATABA Sayembara," anggota berkompetisi mengirimkan tulisan untuk dipublikasikan di media sosial. Kegiatan yang berkelanjutan ini akan menunjang anggota untuk pandai mengasah kemampuan analisis dan memperbanyak bahan bacaan. Hingga saat ini, banyak karya anggota KATABA yang sudah dipublikasikan oleh media lokal, nasional, bahkan internasional dan menjuarai kompetisi-kompetisi kepenulisan nasional.

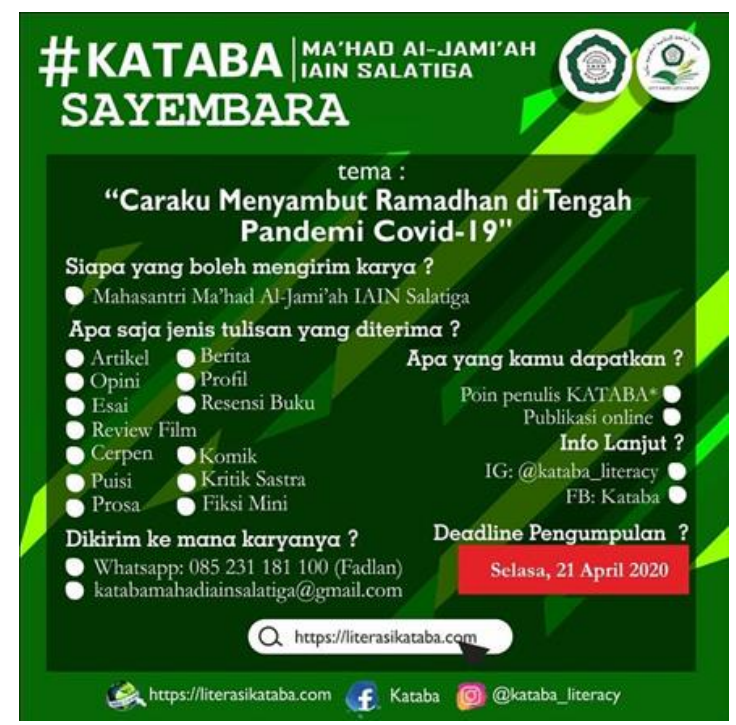

Gambar 4. KATABA Sayembara Karya

Untuk menunjang berbagai kegiatan KATABA, terdapat fasilitas majalah dinding bernama KATABA Wonder Wall. Mading ini menjadi media anggota untuk berkarya. Di samping itu, situs katabaliterasi.blogspot.com menjadi media untuk penyebaran karya secara online. 
Kegiatan tahunan KATABA adalah menggelar seminar dan talkshow literasi nasional. Pada tanggal 16 November 2019, KATABA menyelenggarakan acara Ngaji Literasi bersama Ahmad Fuadi yang merupakan salah satu penggiat literasi yang telah menciptakan banyak sekali karya-karya sastra.

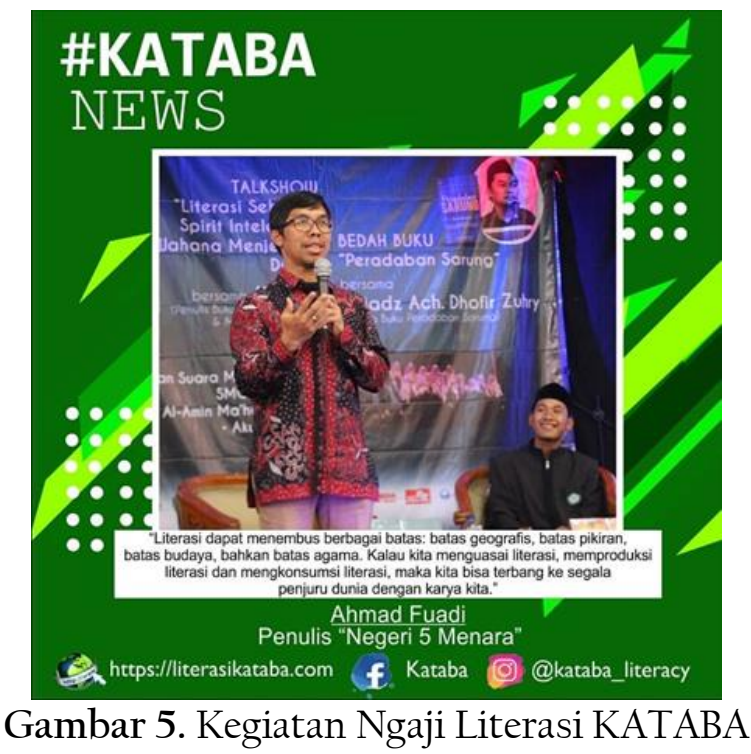

Keberadaan KATABA berdampak baik pada akademik anggota di bidang akademik perkuliahannya. Banyak anggota aktif mengikuti kegiatan-kegiatan kepenulisan nasional, lomba-lomba, konferensi internasional, ataupun presenter dalam seminar.

\section{Surat Al-‘Alaq Ayat 1-5 sebagai Dasar KATABA}

Kegiatan membaca adalah perintah aplikatif yang tersurat dalam wahyu pertama Al-Qur'an surat Al-'Alaq ayat 1-5. Menurut Muhammad Abduh, perintah membaca bukan perintah taklifi (hukum yang berisikan pembebanan atau penyematan status hukum pada perbuatan manusia) melainkan perintah takwini (hukum yang tidak dapat dipengaruhi oleh manusia), yaitu hendaklah engkau menjadi seorang pembaca yang mahir dengan qudrat dan iradat-Ku (Mustolehudin, 2011). Membaca dalam konteks Al-Qur'an surat Al-'Alaq ini mempunyai makna bahwa dengan membaca manusia akan memperoleh ilmu pengetahuan.

Yusuf Qardhawi mengungkapkan bahwa ayat pertama yang diturunkan kepada Rasulullah SAW merupakan petunjuk akan keutamaan belajar dan ilmu pengetahuan. Perintah membaca merupakan kunci ilmu pengetahuan dan alat untuk mentransformasikannya menggunakan qalam (Qardhawi, 1998). Menurut Quraish Shihab kata iqra' mempunyai arti membaca, menelaah, menyampaikan dan sebagainya (Mustolehudin, 2011). Objek dalam Al-Qur'an surat Al-'Alaq ayat 1-5 bersifat universal dan umum yang memiliki makna bahwa kata tersebut mencakup segala yang dapat dijangkau, baik menyangkut ayat-ayat yang tertulis maupun yang tidak tertulis. Perintah membaca dan menulis dalam surat Al-'Alaq 
mempunyai maksud agar umat manusia memiliki pengetahuan, melek huruf dan melek informasi.

Membaca adalah mengeja atau melafalkan apa yang tertulis di dalam kertas (buku), Al-Qur'an atau alat lainnya (mesin ketik, komputer, handphone, laptop) dengan mengetahui makna yang terkandung dalam tulisan tersebut, serta di dalam membaca senantiasa didasarkan kepada kebesaran Allah SWT, karena sesungguhnya kemampuan manusia adalah terbatas (Mustolehudin, 2011). Secara perspektif yang lebih luas, membaca menurut ajaran Al-Qur'an adalah membaca ayat-ayat Allah SWT baik yang tersirat maupun yang tersurat dengan mengetahui makna dan artinya serta mampu mengamalkan ajaran-ajaran yang terkandung di dalamnya.

Pengulangan perintah membaca dalam surat Al-'Alaq memiliki arti bahwa membaca adalah hal mutlak bagi manusia untuk memperoleh ilmu pengetahuan dan informasi. Ayat setelahnya dijelaskan bahwa perintah membaca harus dilandasi dengan mengingat kebesaran Allah SWT. Ayat ketiga dan keempat bermakna bahwa kata qalam adalah hasil dari penggunaan alat tersebut, yaitu tulisan. Qalam atau pena sebagai sarana untuk menulis adalah sumber bacaan yang menjadi pengetahuan bagi manusia. Lima ayat surat Al'Alaq ini menunjukan keutamaan membaca, merenung, dan menulis secara satu kesatuan terintegrasi. Membaca, merenung, dan menulis ini tidak hanya diartikan secara tersurat saja, namun juga perlu diartikan secara tersirat agar kita mengetahui hikmah dan pesan yang terkandung di dalam wahyu Allah yang pertama tersebut (Adib, 2019).

\section{Kontekstualisasi Konsep Literasi Surat Al-'Alaq Ayat 1-5 dalam Kegiatan KATABA}

Lima ayat pertama surat Al-'Alaq mengandung sebuah konsep literasi terintegrasi antara membaca, merenung (kontemplasi) dan menulis. Jika dilihat dari kegiatan KATABA, maka terdapat relevansi antara kegiatan KATABA dalam membumikan literasi perspektif Al-'Alaq ayat 1-5.

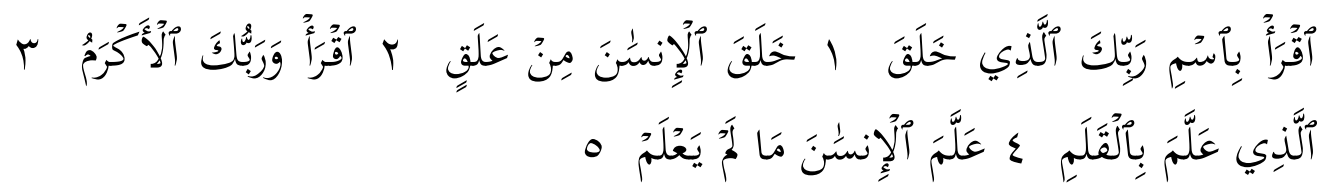

Artinya: "Bacalah dengan (menyebut) nama Tuhanmu Yang menciptakan, Dia telah menciptakan manusia dari segumpal darah. Bacalah, dan Tuhanmulah Yang Maha Pemurah, Yang mengajar (manusia) dengan perantaran pena, Dia mengajar kepada manusia apa yang tidak diketahuinya".

Konsep literasi yang terkandung dalam surat Al-'Alaq ayat 1-5 secara

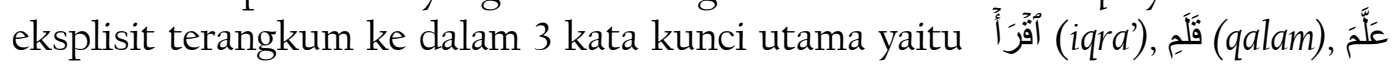
('allama). Ketiga pilar tersebut yang menjadi dasar atau konsep literasi yang bernafaskan Islam. Tiga pilar tersebut menjadi titik tolak kemajuan pendidikan melalui transfer ilmu pengetahuan (Ibtyah, 2019). 


\section{a. Membaca}

Dalam surat Al-'Alaq ayat 1-5, istilah membaca disimbolkan dengan kata آَقَرَأ (iqra'). Kata iqra' dalam surat tersebut terdapat pada ayat pertama dan ketiga. Pada ayat pertama, konsep membaca harus diawali dengan niat dan ikhlas, prinsip ikhlas yang dimaksud ialah membaca harus dengan nama Allah SWT, agar ilmu yang diperoleh dari hasil membaca dapat diridai oleh-Nya. Selanjutnya pada ayat ketiga, Allah kembali memerintahkan untuk terus membaca, karena untuk mendapatkan ilmu dan iman harus terus membaca berkali-kali (minimal dua kali) (Kemenag, n.d.).

Konsep membaca (iqra') yang termaktub dalam surat Al-'Alaq selaras dengan kegiatan komunitas KATABA yaitu kegiatan "One Day Fifteen Minutes Reading". Anjuran membaca 15 menit setiap hari menjadi suplemen penting dalam upaya menggali dan meng-update keilmuan. Melalui aktivitas membaca, dapat melatih dan mengaktifkan daya berpikir kritis (critical thinking). Karena era saat ini, orang dengan cara berpikir kritis tinggi dan memiliki ide inovatif lebih diutamakan.

\section{b. Menulis}

Berkenaan dengan aktivitas menulis, dalam surat Al-'Alaq ayat 1-5 disimbolkan dengan kata (qalam). Kata qalam terdapat pada ayat keempat yang memiliki makna "pena". Makna pena diartikan sebagai alat untuk menuliskan temuan atau ilmu pengetahuan yang didapatkan dari hasil membaca. Sehingga tulisan tersebut dapat dibaca dan dikaji oleh banyak orang dan generasi berikutnya. Dengan demikian ilmu pengetahuan akan terus berkembang dan berkelanjutan (sustainable) (Kemenag n.d.).

Aktivitas menulis juga dilakukan oleh para anggota KATABA, dimana melalui kegiatan "One Month One Creation" dan "KATABA Sayembara" para anggota dilatih untuk menuliskan pengetahuan yang diperoleh dari hasil membaca dan dikaitkan dengan isu-isu terkini. Sehingga aktivitas membaca dan menulis memiliki korelasi yang sangat erat, karena seseorang tidak dapat menulis tanpa memiliki sumber bacaan yang mumpuni.

\section{c. Mengajarkan}

Mengajar merupakan aktivitas yang dilakukan dalam upaya menjaga keberlangsungan ilmu pengetahuan. Dalam surat Al-'Alaq 1-5, makna pengajaran atau mengajarkan disimbolkan dengan kata عَلَّم ('allama). Kata 'allama tertulis pada ayat keempat dam kelima. Dua ayat tersebut menjelaskan bagaimana cara Allah SWT memberikan pengajaran kepada manusia, yaitu dengan melalui pena atau tulisan yang diharuskan kepada manusia untuk membacanya, dan memberikan pengajaran secara langsung tanpa melalui media pena atau alat lainnya, yang selanjutnya dikenal dengan ilmu laduni (Arifah et al., 2020).

Spirit mengajarkan dalam kegiatan literasi KATABA didasarkan pada surat Al-'Alaq ayat keempat dan kelima. Melalui kegiatan "Sabtu Literasi" dan "Ngaji Literasi" dengan konsep diskusi interaktif. Kegiatan tersebut menghadirkan expert dan orang yang lebih berpengalaman dalam bidang kepenulisan untuk memberikan insight kepada para anggota. 


\section{E. Kesimpulan}

Konsep literasi perspektif Al-Alaq ayat 1-5 adalah konsep literasi produktif yang mengintegrasikan antara membaca dan menulis. Jarak antara membaca dan menulis adalah analisis yang membutuhkan sebuah kontemplasi dan perenungan ilmiah. Konsep ini sangat relevan untuk digunakan di era masyarakat society 5.0 yang menuntut generasi milenial untuk kompetitif dalam menghasilkan karya disruptif. Kegiatan yang telah diaplikasikan KATABA merupakan sebuah manifestasi dan implementasi kandungan Al-Alaq ayat 1-5 yang baik dan dianjurkan untuk dapat disosialisasikan kepada mahasiswa dan masyarakat umum.

\section{BIBLIOGRAFI}

Adib, M. A. (2019). Nilai-Nilai Pendidikan Islam dalam Surat Al Alaq Ayat 1-5 Menurut Tafsir Al Misbah dan Penerapannya dalam Pembelajaran. Skripsi. UIN Maulana Malik Ibrahim.

Agustinova, D. E. (2015). Memahami Metode Penelitian Kualitatif: Teori dan Praktik. Yogyakarta: Calpulis.

Ahmad, I. (2018). Proses Pembelajaran Digital dalam Era Revolusi Industri 4.0. https://www.academia.edu/37638057/Proses_Pembelajaran_Digital_dalam_ Era_Revolusi_Industri_4_0_Direktur_Jenderal_Pembelajaran_dan_Kemahasi swaan

Arifah, A. N., Mansur, R., \& Rodafi, D. (2020). Konsep Belajar Dalam Al-Qur'an (Telaah Tafsir Al-Misbah Surat Al-'Alaq Ayat 1-5). Vicratina: Jurnal Pendidikan Islam, 5(5), 115-125.

Badan Penilaian Pendidikan Balitbang. (2019). PISA 2018: Akses Meluas, Saatnya Tingkatkan Kualitas. https://simpandata.kemdikbud.go.id/index.php/s/BTKR4cP76DK3pqM\#pd fviewer

Flewitt, R., Messer, D., \& Kucirkova, N. (2014). New directions for early literacy in a digital age: The iPad. Journal of Early Childhood Literacy, 15(3), 1-22.

Ibtyah, N. R. (2019). Urgensi Literasi Perspektif Q.S. Al-"Alaq Ayat 1-5. Skripsi. UIN Sunan Ampel.

IDN Research Institute. (2019). Indonesia Millennial Report 2019. https://cdn.idntimes.com/content-documents/indonesia-millennial-report2019-by-idn-times.pdf

Karinov. (2019). Revolusi Industri 5.0 ala Jepang: Human-Centered Society. https://karinov.co.id/revolusi-industri-5-jepang/

Kementerian Agama. (n.d.). Qur'an Kemenag: Terjemah Surat Al-Alaq. https://quran.kemenag.go.id/sura/96

Majid, Z. A. (2019). Refleksi Al-Qur'an Dalam Literasi Global (Studi Tafsir Maudhu'i Dalam Kajian Literasi). Al Marhalah: Jurnal Pendidikan Islam, 3(2), 81-90.

Mustolehudin. (2011). Tradisi Baca Tulis Dalam Islam Kajian terhadap Teksi AlQur'an Surah Al 'Alaq Ayat 1-5. Analisa, 18(1), 145-154. 
OECD. (2019). PISA 2018 Results (Volume I): What Students Know and Can Do. Paris: OECD Publishing.

Qardhawi, Y. (1998). Al-Qur'an Berbicara tentang Akal dan Ilmu Pengetahuan. Jakarta: Gema Insani.

Raco, J. R. (2010). Metode Penelitian Kualitatif: Jenis, Karakteristik dan Keunggulannya. Jakarta: Grasindo.

UNESCO. (2003). The Prague Declaration “Towards An Information Literate Society."

Wahidin, U., Islam, Y. M., \& Fadillah, P. (2017). Literasi Keberagamaan Anak Keluarga Marjinal Binaan Komunitas di Kota Bogor. Edukasi Islami: Jurnal Pendidikan Islam, 6(12), 125-135. 